WSRC-TR-92-077

\title{
SHIELD VERIFICATION AND VALIDATION ACTION MATRIX SUMMARY (U)
}

by C. Boman

WSRC-TR--92-077

Westinghouse Savannah River Company

Savannah River Site

DE93 003323

Aiken, South Carolina 29808

This paper was prepared in connection with work done under Contract No. DE-AC09-89SR18035 with the U. S. Department of Energy. By acceptance of this paper, the publisher and/or recipient acknowledges the U. S. Government's right to retain a nonexclusive, royalty-free license in and to any copyright covering this paper, along with the right to reproduce and to authorize others to reproduce all or part of the copyrighted paper.

\section{MASTER}




\section{DISCLAIMER}

This report was prepared as an account of work sponsored by an agency of the United States Government. Neither the United States Government nor any agency thereof, nor any of their employees, makes any warranty, express or implied, or assumes any legal liability or responsibility for the accuracy, completeness, or usefulness of any information, apparatus, product, or process disclosed, or represents that its use would not infringe privately owned rights. Reference herein to any specific commercial product, process, or service by trade name, trademark, manufacturer, or otherwise does not necessarily constitute or imply its endorsement, recommendation, or favoring by the United States Government or any agency thereof. The views and opinions of authors expressed herein do not necessarily state or reflect those of the United States Government or any agency thereof.

This report has been reproduced directly from the best available copy.

Available to DOE and DOE contractors from the Office of Scientific and Technical Information, P.O. Box 62, Oak Ridge, I. 37831; prices available from (615) 576-8401, FTS 626-8401.

Available to the public from the National Technical Information Service, U.S. Defartment of Commerce, 5285 Port Royal Rd., Springfield, VA 22161. 
W S R C - T R-92-077

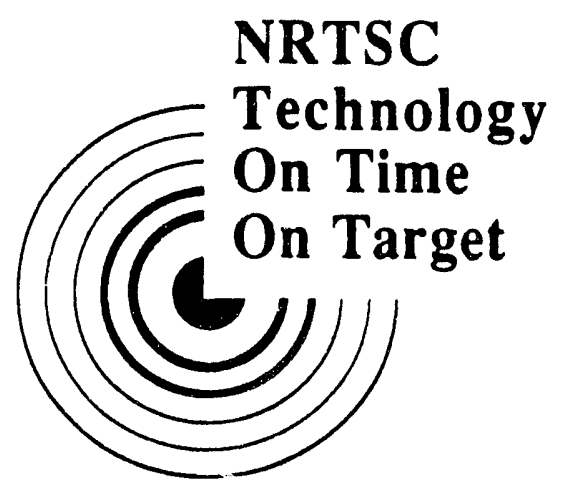

KEY WORDS:

SHIELD

VALIDATION

VERIFICATION

CERTIFICATION

RETENTION PERIOD:

LIFETIME

\section{SHIELD VERIFICATION AND VALIDATION ACTION MATRIX SUMMARY (U).}

\section{B y}

Christa Boman

ISSUED: February 1992

SRL SAVANNAH RIVER LABORATORY, AIKEN, SC 29808 Westinghouse Savannah River Company Prepared for the U. S. Department of Energy under Contract DE-AC09.88SR 18035 
DOCUMENT: WSRC-TR-92.077

TITLE: SHIELD VERIFICATION AND VALIDATION ACTION MATRIX SUMMARY (U).

TASK: CERTIFICATION PLAN FOR SHIELd (91-013-1)

APPROVALS

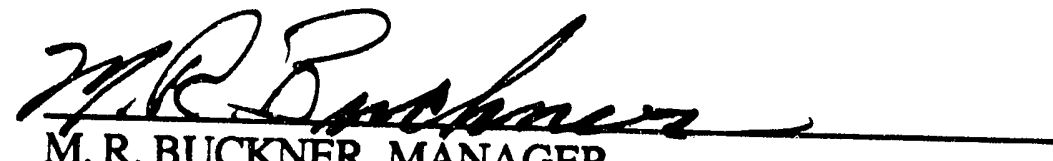

M. R.BUCKNER, MANAGER

DATE 2-19-92

SCIENTIFIC COMPUTATIONS SECTION

$\frac{\text { C.E. Cspeen }}{\text { C. E. APPERSON, MANAGER }}$

REACTOR PHYSICS GROUP

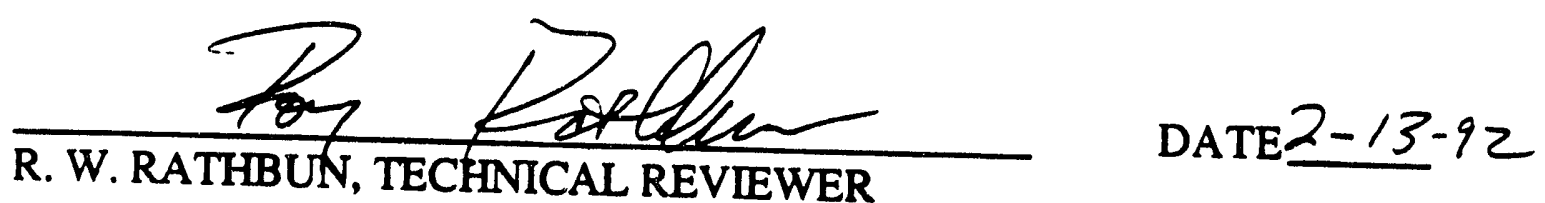




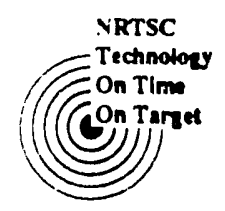

SHIELD Verification and Validation

WSR C.TR-92.077

February, 1992 Action Matrix Summary

Page 1 of 12

\subsection{SUMMARY}

WSRC-RP-90-26, Certification Plan for Reactor Analysis Computer Codes (U) (Ref. 1), describes a series of action items to be completed for certification of reactor analysis computer codes used in Technical Specifications development and for other safety and production support calculations. Validation and verification are integral part of the certification process (Ref. 2). This document identifies the work performed and documentation generated to satisfy these action items for the SHIELD, SHLDED, GEDIT, GENPRT, FIPROD, FPCALC, and PROCES modules of the SHIELD system, it is not certification of the complete SHIELD system. Complete certification will follow at a later date. Each action item is discussed with the justification for its completion. Specific details of the work performed are not included in this document but can be found in the references. The validation and verification effort for the SHIELD, SHLDED, GEDIT, GENPRT, FIPROD, FPCALC, and PROCES modules of the SHIELD system computer code is completed.

\subsection{INTRODUCTION}

WSRC-RP-89-1249, Verification and Validation Plan for Reactor Analysis Computer Codes (Ref. 2), describes a series of action items to be completed for verification and validation of reactor analysis computer codes used in Technical Specifications development and for other safety and production support calculations. These requirements have been organized into an action matrix. Each action item describes the different type of information and documentation that must be assembled for each code to be certified. The action matrix serves as a useful tracking tool for monitoring completion of the certification process for individual codes.

Figure 1 shows the present status of the action matrix for the the SHIELD, SHLDED, GEDIT, GENPRT, FIPROD, FPCALC, and PROCES modules of the SHIELD system computer code. As can be seen in the figure, all the requirements for verification and validation of the code have been completed with the exception of the review process. The rest of this document gives the justification for checking each box in turn and identifies all relevant reference documentation. 


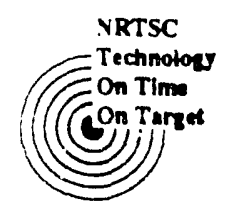

SHIELD Verification and Validation

WSR C-TR-92-077

Action Matrix Summary

February, 1992

Page 2 of 12

The action matrix (Figure 1) divides the activities into five groups: Basics, Theory, Experiments, Benchmarks, and Conclusions. The remainder of this report utilizes the same structure and format.

\subsection{ACTION MATRIX}

\subsection{BASIC REQUIREMENTS}

\subsubsection{User's Manual in Place}

User documentation for the SHIELD computer code is contained in the The SHIELD System User's Manual (Ref. 3). This document provides all the necessary information for knowledgeable individuals to utilize the SHIELD code providing they are farmiliar with the WSRC computer facilities and the JOSHUA (Ref. 4) system. The user's manual explains how to set up and interpret results from all of the important calculations performed using the SHIELD code.

Chapters I and II of the user's manual present an introduction and overview of the SHIELD system and of the associated supporting nuclear data libraries. These chapters also describe the general class of problems that can be solved with the SHIELD system. Chapter III describes the conventions used to execute a problem using the SHIELD system. Detailed input instructions for the individual calculation types are described in chapter IV. Chapter V lists references.

Following the five chapters are a series of appendices: Appendix A provides information on the nuclear data base; Appendix B describes test problems; Appendix C documents validation studies; Appendix D documents the SHIELD system input record formats; Appendix E describes support data sets and record formats; and, Appendix $G$ provides documentation on the peer review of the SHIELD system.

In addition to the use:'s manual, a SHIELD User's Notice (Ref. 5) has been issued which proyides information about the location of the J80 version of SHIELD, instructions for executing SHIELD, information about user levels, and training requirements. 


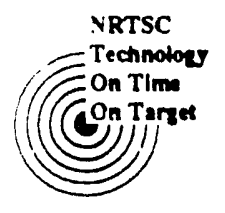

SHIELD Verification and Validation

WSRC-TR-92.077

Action Matrix Summary

February, 1992

Page 3 of 12

\subsubsection{Configuration Control Plan}

The Configuration control plan for the reactor analysis computer codes, including the SHIELD code, is given in the Certification Plan for Reactor Analysis Computer Codes (Ref. 1). Configuration control of the SHIELD code is implemented by following Procedure No. TP-90-018: Responsibilities of Technical Proprietors for Configuration Management Using SCMS (Ref. 6). A configuration controlled version of SHIELD on the IBM 3090 under the J80 version of JOSHUA has been installed. The source code for the SHIELD system modules currently being certified is stored under the Scientific Code Management System, which protects it from unauthorized changes, and ensures strict quality assurance standards are adhered to. The source listing for the SHIELD, SHLDED, GEDIT, GENPRT, FIPROD, FPCALC, and PROCES modules of the SHIELD system are located on the VAX cluster, in the SCMS libraries SRLUSER3:[SCMS.SOURCE.SHIELD]. The executable J80 version of SHIELD has also been stored under the Scientific Code Management System. The executable SHIELD, SHLDED, GEDIT, GENPRT, FIPROD, FPCALC, and PROCES modules are located on the IBM 3090 in the data set USCS.SCMS.LOAD.

Instructions for executing SHIELD on the IBM under J80 can be found in Ref. 5. A set of test problems has been developed which span the range of applications of the SHIELD modules being certified. The input and output from these problems are detailed in Ref. 7. The test problems can be found on the IBM in the data set USCS.SCMS.TEST.

\subsubsection{Code Portability}

SHIELD has been converted to standard FORTRAN 77, a machine independent language. However, SHIELD is intimately tied to the JOSHUA system, which is machine dependent. Therefore, the portability of SHIELD is dependent upon the portability of the JOSHUA system. SHIELD, and the JOSHUA system, were originally written on the IBM mainframes at the SRS; currently they run on the IBM 3090 . Limited portability of JOSHUA has been demonstrated and additional portability can be implemented if the need arises. 
WSR C - T R-92.047

SHIELD Verification and Validation

February, 1992

Action Matrix Summary

Page 4 of 12

\subsection{VERIFICATION OF THEORY}

\subsubsection{Appropriate Theory}

The theory of the FIPROD, FPCALC and PROCES modules are described here.

The decay and/or buildup of radioactive nuclides under conditions of spontaneous decay is solved by modules FIPROD and FPCALC. The FIPROD module calls the FPCALC module to perform the actual productiondepletion calculation using either the linearized chain or matrix exponential mathematical algorithms. The time dependent isotopic composition is solved for using a first order differential equation for burnup. The FPCALC module being certified here assumes space independent fluxes and cross sections, or that any space dependence of fluxes and cross sections has been averaged into the input information. FIPROD is also capable of performing a cooling calculation which computes the isotopic inventory of radionuclides under zero-flux conditions.

Two mathematical algorithms are available in the FIPROD module for the burnup or cooling ulations. The LINCHAIN option approximates the coupling matrix berween isotopes to a vector repres.tation and solves the vector problem by an explicit solution. This mathematical algorithm is similar to that used in the CINDER code (Ref. 9). The MATEXP option uses the matrix exponential approximation to the full matrix solution. This mathematical algorithm is the same used in the ORIGEN code (Ref. 10).

The PROCES module of the SHIELD system simulates the mechanical and chemical fuel cycle processes. The quantity conserved in the normal fuel cycle calculation is the total mass of each isotope that enters and leaves a process vessel. More detailed solution method descriptions of FIPROD, FPCALC, and PROCES can be found in Ref. 3, The SHIELD System User's Manual.

The theory described above are all industry accepted approaches (Ref. 11 \&12). The theory employed by the SHIELD code is appropriate for the types of problems it is intended to solve. 


\subsubsection{Theory Documented}

The SHIELD code theory documented in Ref. 3 is described in detail in standard nuclear analysis methodology texts such as Refs. 11 \& 12 . Since no new theoretical development is introduced, the basic theory as documented in the open literature provides conceptual verification of the code theory as required.

\subsubsection{Coding Consistency}

The SHIELD code was developed long before the current validation and verification requirements were in place and as a result the verification performed at the time was not documented sufficiently to meet current requirements. Retroactively verifying line by line the coding of such a large software system as SHIELD would be a monumental task and it has not been deemed necessary. The extensive operations history of SHIELD, in conjunction with the code validation discussed below, is sufficient to establish that the code is functioning as intended and therefore this item is satisfied.

\subsubsection{Theory Verified Conceptually}

The SHIELD code theory is summarized in Ref. 3. Since no new theoretical development is introduced, the basic theory as documented in the open literature and the description of the code function provide conceptual verification of the code theory as required.

\subsubsection{Theory Verified by Experiment}

The SHIELD code was developed long before the current validation and verification requirements were in place and as a result the verification performed at the time was not documented sufficiently to meet current requirements. The extensive operations history of SHIELD, however, in conjunction with the code validation discussed below is sufficient to establish that the code is functioning as intended. The validation process is described in SHIELD Verification and Validation Report (Ref. 13). 


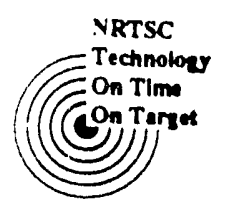

SHIELD Verification and Validation

WSR C-TR-92.077

Action Matrix Summary

February, 1992

Page 6 of 12

\subsubsection{Theory Documentation Adequate}

The techniques employed by the applicable SHIELD modules are well documented in the open literature. The documentation is adequate to demonstrate the adequacy of the theory.

\subsection{VALIDATION WITH EXPERIMENTS}

\subsubsection{Tests in Experimental Facilities}

Tests have been performed in experimental facilities at Oak Ridge National Laboratory (ORNL) and Los Alamos National Laboratory (LANL) and the results have been used to validate SHIELD (Refs. 14-16).

\subsubsection{Tests in Operating Facilities}

No tests in operating facilities were used for the validation of SHIELD. This item is not required for validation because other means of validation have been demonstrated.

\subsubsection{Data from Operating Facilities}

Measurements were made in the SRS separations area for fission product activities in discharged Mark 22, 16B and 53B assemblies and decay heat in Mark 22, 16B, 31 A and 31B assemblies (Refs. 17-20).

\subsubsection{Test Data Documented}

A body of data has been identified and documented (Refs. 3 \& 14-20). Conditions under which the data were collected can be determined with reasonable assurance in the references. Documentation of these test are in the open literature.

\subsubsection{Appropriate Data Quality}

All relevant experimental and operating data were taken prior to present QA standards being adopted. Standard data acquisition methods and 


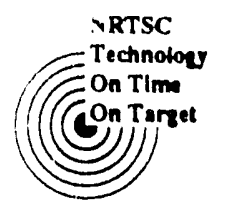

SHIELD Verification and Validation

WSR C-T R-92.077 Action Matrix Summary

February, 1992

Page 7 of 12

techniques were used in experimental facilities at LANL, ORNL and SRS.

\subsubsection{Validation Performed}

The SHIELD code has been validated against both experimental and operating data. The code features and models that have been validated are described in SHIELD Verification and Validation Report (Ref. 13), and the actual validations are summarized in earlier validation documents (Ref. 3 \& 21). These documents received in-depth technical reviews.

\subsubsection{Validation Documentation Adequate.}

This item was satisfied by technical review of the SHIELD Verification and Validation Report (Ref. 13).

\subsection{VALIDATION BY BENCHMARKING}

\subsubsection{Benchmark Requirements Identified}

Benchmark requirements are listed in Ref. 3.

\subsubsection{Similar Code Comparison}

The FIPROD and FPCALC calculations were compared to CINDER (Ref. 9) and ORIGEN (Ref. 10) results as documented in the SHIELD Verification and Validation Report (Ref. 13).

\subsubsection{Exact Solution Comparison}

Sample problems for the PROCES and EDIT modules were made trivial so that hand calculations were possible for verification. Comparisons of PROCES results to hand calculations show exact agreement (Ref. 22).

\subsubsection{Industry Benchmark Comparisons}

No industry benchmark cases have been used in the validation of SHIELD. This item is not required for validation because other means of validation 
SHIELD Verification and Validation

have been demonstrated.

\subsubsection{Comparisons Documented}

The results of the benchmarking are documented in the references given in SHIELD Validation and Verification Report (Ref. 13). Two documents in particular (Refs. 3 and 21 of this docu nt) summarize most of this information and satisfy the document. in requirements.

\subsubsection{Benchmark Documentation Adequate}

The benchmark documentation contained in SHIELD Validation and Verification Report (Ref. 13) is adequate for validation of the SHIELD code.

\subsubsection{Standard Set of Test Problems}

A standard set of test problems has been developed and documented (Ref. 7). Complete input and output for these problems is provided in the documentation, ar the test roblems sue been piaced in protected data sets.

\subsection{CONC. SIONS}

Verification and validation/benchmarking of the SHIELD code as outlined in Ref. 1 is now completed. 


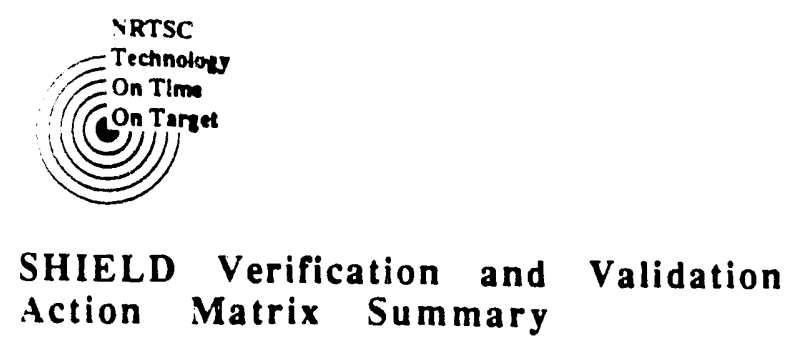

WSR C.TR.92.077

February, 1992

Page 9 of 12

\begin{tabular}{|c|c|c|c|c|}
\hline & & RESULTS & INITIALS & DATE \\
\hline Basics & $\begin{array}{l}\text { User Manuals in Place } \\
\text { Configuration Control Plan } \\
\text { Code Pcrtability }\end{array}$ & $\frac{\frac{\text { yes }}{\text { yes }}}{\text { yes }}$ & $\frac{\frac{C \beta}{c B}}{c \beta}$ & $\frac{2 / 7 / 92}{2 / 12 / 92}$ \\
\hline Theory & $\begin{array}{l}\text { Appropriate Theory } \\
\text { Theory Documented } \\
\text { Coding Consistency } \\
\text { Theory Verified Conceptually } \\
\text { Theory Verified by Experimente } \\
\text { Theory Documentation Adequate }\end{array}$ & $\frac{\frac{\text { yes }}{\text { yes }}}{\frac{\text { yes }}{\text { yes }}}$ & $\frac{\frac{c \beta}{C \beta}}{\frac{c \beta}{c \beta}} \frac{c \beta}{\frac{C \beta}{C \beta}}$ & $\frac{217 / 92}{\frac{211192}{217192}} \frac{217192}{2 \sqrt{1 / 92}}$ \\
\hline Experiments & $\begin{array}{l}\text { Teato in Experimental Facilities } \\
\text { Teats in Operating Facilities } \\
\text { Data from Operating Facilities } \\
\text { Teat Data Documented } \\
\text { Appropriate Data Quality } \\
\text { Validation Performed } \\
\text { Validation Documentation Adequate }\end{array}$ & $\frac{\frac{\text { jes }}{\text { N.t }}}{\text { yes }}$ & $\frac{\frac{c G}{c B}}{\frac{c \beta}{C B}} \frac{\frac{C B}{C B}}{\frac{C B}{C B}}$ & $\begin{array}{l}\frac{217 / 92}{21792} \\
\frac{217192}{21792} \\
\frac{21792}{21792} \\
\frac{21792}{219}\end{array}$ \\
\hline Benchmarks & $\begin{array}{l}\text { Benchmark Requirements Identifled } \\
\text { Similar Code Comparienn } \\
\text { Ezact Solution Comparison } \\
\text { Industry Benchmark Comparieon } \\
\text { Comparieons Documented } \\
\text { Benchmark Documentation Adequate }\end{array}$ & $\frac{\frac{y e s}{\text { yes }}}{\frac{\text { yes }}{\text { yes }}} \frac{\text { yes }}{\frac{\text { yes }}{}}$ & $\frac{\frac{C \beta}{C \beta}}{\frac{C \beta}{\frac{C \beta}{C \beta}}}$ & $\begin{array}{l}2 / 7192 \\
2 \sqrt{792} \\
2 \sqrt{992} \\
2 \sqrt{192} \\
2 / 792 \\
27 \sqrt{92}\end{array}$ \\
\hline Conclusions & $\begin{array}{l}\text { Verification review } \\
\text { Verification Completed } \\
\text { Standard Set of Teat Problems } \\
\text { Validation/Benchmarking Review } \\
\text { Validation/Benchmarking Completed }\end{array}$ & $\frac{\frac{\text { yes }}{\text { yes }}}{\frac{\text { tes }}{\text { yes }}}$ & $\frac{\frac{C \beta}{C \beta}}{\frac{C \beta}{C \beta}}$ & 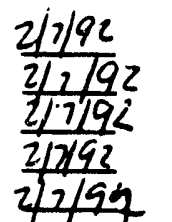 \\
\hline
\end{tabular}

\title{
Verification and Validation Plan Action Matrix for SHIELD
}

\author{
Figure 1
}




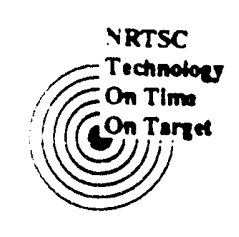

SHIELD Verification and Validation

WSR C-T R-92.077

Action Matrix Summary

February, 1992

Page 10 of 12

\subsection{REFERENCES}

1. H. Toffer, R.D. Crowe, K.N. Schwinkendorf, and R.E. Pevey, Certification Plan for Reactor Analysis Computer Codes (U), WSRC-TR-90-26, January, 1990.

2. H. Toffer, R.D. Crowe, K.N. Schwinkendorf, and R.E. Pevey, Veritiation and Validation Plan for Reactor Analysis Computer Codes (U), WS C-RP89-1249, November, 1989.

3. D. R. Finch, The SHIELD System User's Manual, DPSTM-87-700-2, October, 1988.

4. H. C. Honeck, The JOSHUA System, DPSTM-500, Vols. 4 and 4.1, 1970.

5. C. Boman, SHIEI.D User Notice \#92-01, SCS-RPG-920034, February, 1992.

6. J. C. Jensen, Responsibilities of Technical Proprietors for Configuration Management Using SCMS, TP-90-018, November, 1990.

7. C. Boman, A Standard Set of Test Problems for SHIELD, WSRC-TR-92075, February 1992.

8. S. H. Finfrock and R. L. Frost, GLASS User's Manual, WSRC-TR-91-143, April, 1991.

9. T. R. England, et al., Fission Product Data for Thermal Reactors. Part 1: A Data Set for EPRI-CINDER Using ENDF/B-IV and Part 2: Users Manual For EPRI-CINDER Code and Data. Electric Power Research Institute, EPRI-NP356, 1970.

10. M. J. Bell, ORIGEN: The ORNL Isotope and Depletion Code, Oak Ridge National Laboratory, ORNL-4628, 1973. 


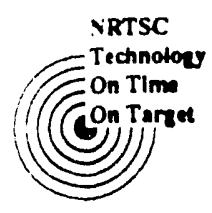

SHIELD Verification and Validation

11. J. R. Lamarsh, Nuclear Reactor Theory, Addison-Wesley Publishing Co., Reading, MA 1966.

12. J. J. Duderstadt, L. J. Hamilton, Nuclear Reactor Analysis, John Wiley \& Sons, New York, 1976.

13. C. Boman, SHIELD Verification and Validation Report, WSRC-TR-92076, February 1992.

14. J. L. Yarnell and P. J. Bendt, Calorimetric Fission Product Decay Heat Measurements for $239 \mathrm{Pu}, 238 \mathrm{U}$, and $235 \mathrm{U}$, Los Alamos Scientific Laboratory, LA-7452-MS, 1978.

15. J. K. Dickens, et al., Fission-Product Energy Release for Times Following Thermal-Neutron Fission of $235 \mathrm{U}$ Between 2 and 14000 Seconds, ORNL/NUREG-34, 1978.

16. J. K. Dickens, et al., Fission-Product Energy Release for Times Following Thermal-Neutron Fission of ${ }^{239} \mathrm{Pu}$ Between 2 and 14000 Seconds, ORNL/NUREG-34, 1978.

17. C. E. Apperson, Application of ANS 5.1 to the Evaluation of Decay Heat Generation in the Mark 16, Mark 31 and Mark 22 Assemblies, DPST-82423, 1982.

18. C. E. Apperson, Fission Product Activity Data Base for Mark 22, DPST82-687, 1982.

19. C. E. Apperson, Fission Product Activity Data Base for Mark 16B, DPST83-481, 1983.

20. W. C. Perkins, et. al., Verification of Computer Calculations for Radioactivity in Neptunium Targets, SRL Monthly Report, DPST-83-1-6, 1983. 
21. J. C. Butler and D. R. Finch, A Validation Comparison of SHIELD System Decay Heat Calculations to Benchmark Quality Experiments, DPST-87-391 (Rev. 1), 1987.

22. A. W. Tipton, SHIELD Proprietor's Notebook, WSRC-NB-90-301. 

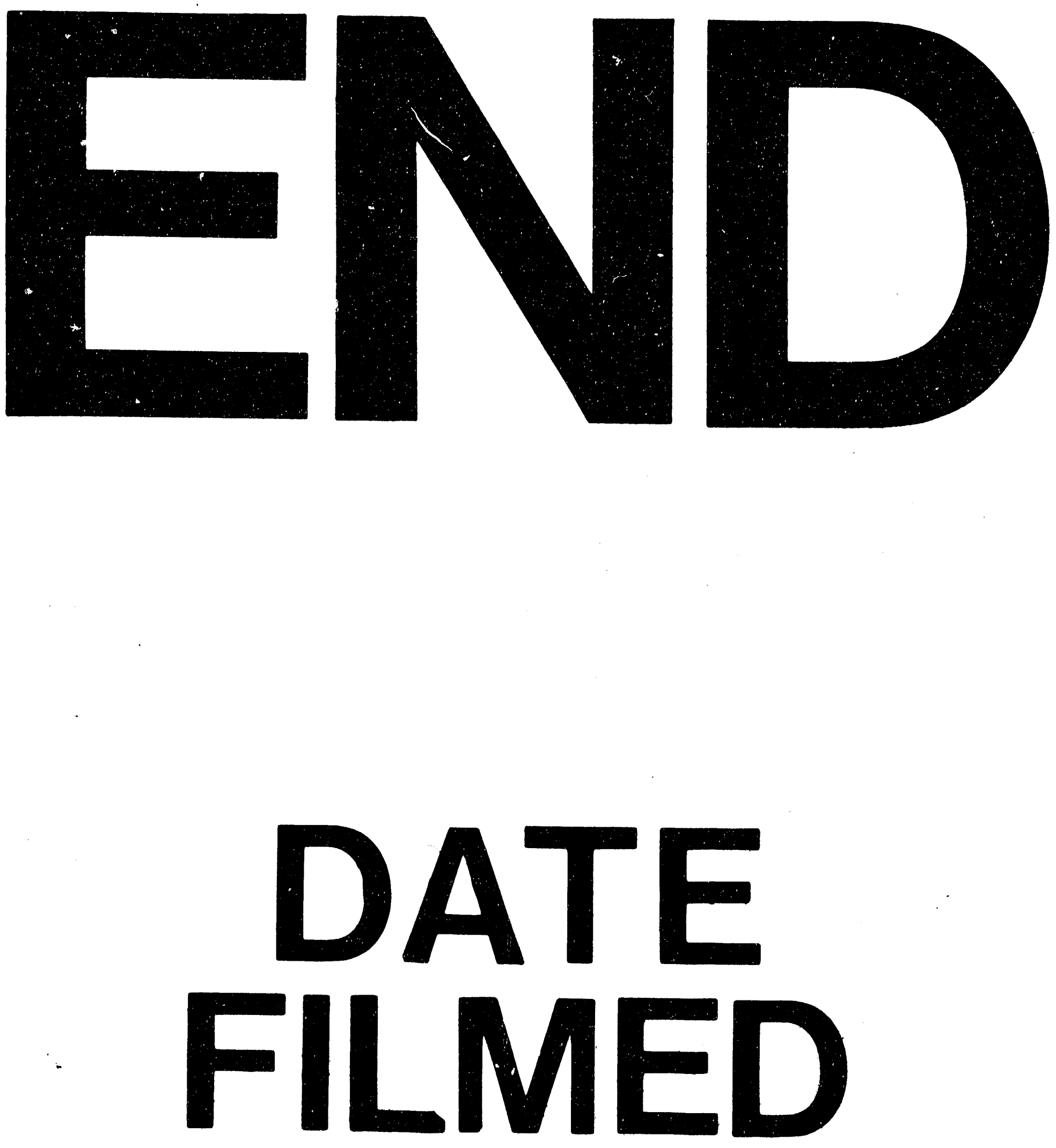

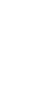
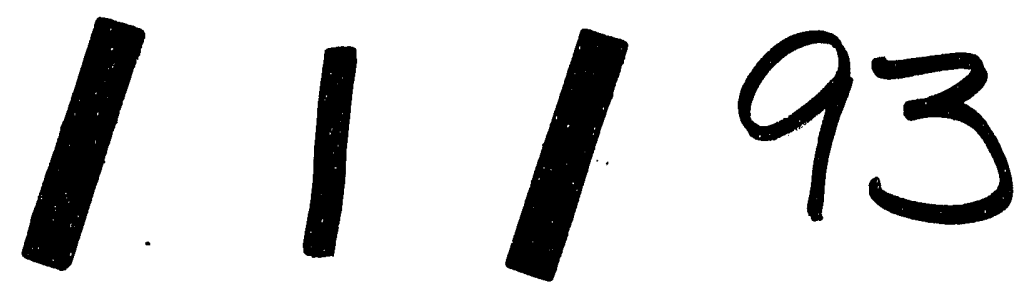
